\title{
Studies on the Peel Oil from Two Varieties of Banana
}

\author{
Z. Hassan, I. A. Jahan*, G. C. Saha, F. Begum, K. Nada and J. Chowdhury \\ ${ }^{a}$ BCSIR Laboratories Dhaka, DR. Kudrat-I-Khuda Road, Dhanmondi, Dhaka-1205
}

\begin{abstract}
Composition of fatty oil in two different varieties of banana peels Mausa Cavendis (sagar kola) and Mausa Sapientum (savrie kola) was determined. Percent fatty oil content was found as 7.5 in savrie and 10 in Sagar peels. Unsaponifiable matter, Iodine value, free fatty acid contents and Saponification value were also determined for both the samples. It was observed that the linoleate content (2.74) in sagar variety is slightly higher than savrie variety (2.41), but the palmitate contents were found as 12.55 and 13.86 , stearate contents 2.62 and 4.57 in Sagar and Savrie variety respectively.
\end{abstract}

Key words: Oil, Saponification value, Iodine value, Banana, Peel

\section{Introduction}

Banana is one of the most important fruits grown round the year over whole of Bangladesh. It is cheaper and consumed in all sectors of people. But its peel is left as waste and scattered in and around or thrown away in the garbage bin. Annual World production of banana is estimated at 75 million tones including approximately 19 million tones of peel (John and Marchel, 1995). In most cases during marketing and consumption it is termed as waste as in the cases of other fruits. However, there are many possible end uses for this waste (Kanazawa and Sakakibara, 2000). In Philippines, peels are sun dried into chips for export to Japan and Taiwan for use as feed fillers in chemical processing (Stover and Simmonds, 1959). In Costa Rica, fiber from banana fruit waste (peel) is combined with office wastepaper to produce recycled paper, cardboard, notepads, envelopes, postcards and notebooks (Anonymous,1995). In Uganda banana peels are used as cattle feed and fuel briquettes. According to Brown and Swinbourn the germination and proliferation of certain fungi are restricted by phytoalexins and other compounds found in the peels (Brown and Swinbourn, 1989).

Different types of bananas are grown in most of the parts of Bangladesh particularly Dhaka and its periphery. It is also grown in abundance in northern zone of the country.

\footnotetext{
* Corresponding author: E-mail: ismet0103@yahoo.com
}

So far reported from local sources as well as $5-6 \%$ of the total banana production is peel. It is almost a fact that cattle's are fond of eating banana peels scattered in and around. Livestock people are not accustomed to contemplate weather banana peel could be incorporated in Cattle ration as feed component. World trend at present directs towards utilizing wastes for useful products. So banana peel should be taken into account for the study of nutritional compounds so that the waste peel could be utilized for feed or feed supplements.

Different varieties of bananas are grown in Bangladesh of which two varieties are popular and abundantly available to the people. In this context sagar (Mausa cavendish) and shavri (Mausa sapientum) have been chosen for the study of nutritional factors. At present we are interested for the study of physicochemical characteristics of the two varieties of fats and oils with a view to knowing whether those varieties contain substantial quantity of component fatty acids or any special factors in them so that those could provide information valuable for utilizing the peel fats for useful purposes.

\section{Materials and Methods}

\section{Extraction of peel oil and fats}

Banana peels $(2.0 \mathrm{Kg})$ were collected, cleaned, cut in to small pieces and blended within minimum quantity of distilled water. Peel paste was then dried in the oven at below 
$50^{\circ} \mathrm{C}$. Dried peels were grounded to obtain fine powder so that maximum particle exposure was got for extraction of oil. $500 \mathrm{~g}$ of powder was subjected to Soxhlet extraction. In this case analytical grade n-Hexane was used as solvent. Extracted oil in solvent was subjected to solvent recovery, and finally brownish oil was obtained. The oil was subjected to physicochemical analyses and finally for acid composition. Three determinations for each of the variety have been done. In the case of physicochemical analysis, important characteristics related to fats and oils, such as, Saponification value and Unsaponifiable matter and Iodine values were determined for each variety.

For the determination of the composition the oils were first esterified then subjected for GC/MS analysis.

\section{Methyl esterification of fatty acids.}

$200 \mathrm{mg}$ of oil for each variety was added to $10 \mathrm{ml}$ methanolic sodium hydroxide taken in a pear-shaped flask. The mixture was refluxed for 10 minutes. After reflux, $5 \mathrm{ml} \mathrm{BF}_{3}$ was added to the mixture. The complex formed was sonicated for 1 minute and again heated on a water bath for 10 minutes for the removal of residual solvents. Finally the mixture was extracted by n-hexane. n-Hexane extracted fraction was filtered and dried finally and subjected to GC/MS study.

\section{Results and Discussion}

Solvent extraction of the peel powder yields $10 \%$ oil in the case of sagar variety, while $7.50 \%$ in the case of savrie variety. From the data it is clear that peel of sagar variety yields oil more than that of savrie variety. The oil yields of both the varieties though not significant in the point of quantity of yield, the significance will be more comprehensive if it is thought to be a waste and thrown. It is referred to the introduction chapter that $5-6 \%$ of the total banana production is peel and it is waste. So this information is sufficient for an entrepreneur to think about industrial extraction of oil.

Table I also comprises physicochemical characteristics of the oil of both varieties. Iodine value of the peel oil of sagar variety is slightly higher than that of savrie variety (103.16 vs. 100.04).

Both the varieties containing linoleate so far significantly. Sagar variety contains slightly higher (2.74) than that of sagar variety 2.41 . Linoleate is an essential fatty acid which
Table I: Chemical characteristics of two varieties of banana peels

\begin{tabular}{l|l|c|c}
\hline No & \multicolumn{1}{|c|}{ Variety } & $\begin{array}{c}\text { Sagar (Mausa } \\
\text { cavendies) }\end{array}$ & $\begin{array}{c}\text { Savrie (Mausa } \\
\text { sapientum }\end{array}$ \\
\hline 1 & Fatty oil (\%) & 10.00 & 7.50 \\
2 & Un saponifiable matter (\%) & 48.81 & 40.00 \\
3 & Iodine value & 103.16 & 100.04 \\
4 & Free fatty acid (\%) & 14.50 & 9.75 \\
& (as oleic acid) & 49.50 & 61.20 \\
\hline
\end{tabular}

could be rapidly supplemented in the food. Significant amount of linoleic acid could be extracted from waste peel. This data is informative to the people who are associated with the food industries. Peel oil could easily be supplemented in the food and feed for the cattle. Oleiate content was found as $1.48 \%$ in sagar variety only which is a good indicator for the people who are manufacturing abrasive and ointment. They may incorporate sagar peel oil in the traditional preparation of abrasive and ointment. The palmitate content was found as 12.55 and 13.86, and stearate contents 2.62 and 4.57 in sagar and savrie variety respectively. It is observed that savrie variety contained higher amounts of both the palmitate and stearate. But the stearate content in both the varieties is not significant to the extent of industrial application in comparison to palmitate content, which rather seems industrially feasible.

Saponication value of the savrie variety oil is higher 61.20 in comparison to sagar, which is 49.50 (Table I). The saponification value here is not promising though the variety contains substantial quantity of saturated saponifiable fatty acids. Sagar variety contains $12.55 \%$ of palmitate whereas savrie contain $13.86 \%$. The percent acid saturated is not ignorable (Table II and III) if it is considered in the angle of waste. Palmitate content of both the varieties could serve as a marker for the soap industry people who may easily incorporate peel oil in soap manufacturing especially palmitate soap. Stearic acid content of both the varieties is not significant. Though the saturated fatty acid content of both the varieties particularly for stearate and palmitate is not significant, still there is an ample scope for the industrial chemists to contemplate about bulk isolation of the oil from waste source so the soap industries of different kind could be initiated.

In regard to unsaponifiable matter content sagar variety contains 48.0 where as savrie variety contains 40.0 (Table I). These results are conformable with the data in the Table II and 
Table II: Analysis of methylated fatty oil of Sagar kola peel (Mausa cavendies)

\begin{tabular}{l|c|c}
\hline No. & Compounds & Percentage \\
\hline 1 & Methyl laurate & 0.26 \\
2 & Methyl myristate & 0.38 \\
3 & Methyl palmitoleate & 0.41 \\
4 & Methyl palmitate & 12.55 \\
5 & Methyl Linoleate & 2.74 \\
6 & Methyl stearate & 2.62 \\
7 & Methyl oleiate & 1.48 \\
8 & Vitamin A aldehydes & 1.04 \\
9 & 5-Cholene, 3, 24-dihydroxy & 50.82 \\
\hline
\end{tabular}

III, because most of the pigmented matters came into unsaponifiable parts. It may be exemplified that 3-24 dihydroxy 5-cholene (Table II and III) in one of the unsaponifiable substance came to be around $50 \%$ in sagar variety

Table III. Analysis of methylated fatty oil of Savrie kola peel (Mausa Sapientum)

\begin{tabular}{l|c|c}
\hline No. & Compounds & Percentage \\
\hline 1 & Methyl palmitate & 13.86 \\
2 & Methyl Linoleate & 2.41 \\
3 & Methyl petroselinate & 5.79 \\
4 & Methyl isostearate & 4.86 \\
5 & Methyl stearate & 4.57 \\
6 & 5-Cholene, 3, 24-dihydroxy & 5.12 \\
7 & 5-Dihydroergosterol & 6.94 \\
8 & 4,8,13-Duvatriene-1, 3-diol & 11.50 \\
9 & Henicosyl formate & 4.31 \\
\hline
\end{tabular}

whereas in savrie variety it was found as $5.12 \%$ only. The high content of this compound in single variety superseded the other variety is point to be thought of. At this stage this finding has been kept aside for further work on this compound. In the scenarios (Table II) vitamin A aldehydes was found as around $1 \%$ in sagar peel oil. This result is quite informative to the person who deals with the traditional medicine. Should proper endeavor is given for the industrial isolation and concentration of vitamin A aldehyde from the unsaponified part of the oil; this would supplement the traditional medicinal industries who deal with tonic and elixir preparation.

\section{References}

Anonymous (1959) Infomusa, International magagine on banana and plantain, 4: $22 \mathrm{pp}$

Brown A. E. and Swinbourn T. R. (1989) The resistance of immature banana fruits to anthracnose Phytopath, 99: 80.

John, P. and Msrchal, J. (1995) Ripening and biochemistry of the fruit. IN: S. Gowen (Ed) Banana and Plantain, Chapman and Hall, London, Pp 434-467.

Kqanazawa K. and Sakakibara H. (2000) High content of dopamine, a strong antioxidant, in Cavendish banana. $J$ Agric Food Chem. 48 (3): 844-848.

Stover R. H and Simmonds, N. W. (1995) Bananas, 3rd ed, $461 \mathrm{Pp}$.

Received : May 25, 2009;

Accepted : August 24, 2009 